\title{
Erratum to metformin up-regulated miR-107 expression and enhanced the inhibitory effect of miR-107 on gastric cancer growth
}

\author{
Yongyi Chen ${ }^{1,2,3}$, Wangang Gong ${ }^{1,2,3}$, Yun Zhou ${ }^{1,2,3}$, Runping Fan ${ }^{1,2,3}$, Yuchen Wu ${ }^{1,2,3}$, Wangwei Pei ${ }^{1,2,3}$, \\ Sufang Sun ${ }^{1,2,3}$, Xiaohong X $\mathbf{u}^{1,2,3}$, Huifen Jiang ${ }^{1,2,3}$ \\ ${ }^{1}$ Institute of Cancer Research and Basic Medical Sciences of Chinese Academy of Sciences, Hangzhou, China; ${ }^{2}$ Department of Clinical Lab, Cancer \\ Hospital of University of Chinese Academy of Sciences, Hangzhou, China; ${ }^{3}$ Department of Clinical Lab, Zhejiang Cancer Hospital, Hangzhou, China \\ Correspondence to: Huifen Jiang. Department of Clinical Lab, Zhejiang Cancer Hospital, No 1, East Banshan Road, Gongshu District, Hangzhou \\ 310022, China. Email: jianghuifentougao@163.com.
}

doi: $10.21037 /$ tcr-2020-007

View this article at: http://dx.doi.org/10.21037/tcr-2020-007

Erratum to: Transl Cancer Res 2020;9:2941-50.

Metformin up-regulated miR-107 expression and enbanced the inbibitory effect of miR-107 on gastric cancer growth

In the April 2020 issue Vol 9, No 4 of Translational Cancer Research, the paper "Metformin up-regulated miR-107 expression and enhanced the inhibitory effect of miR-107 on gastric cancer growth", 2020 Mar; 9(4): 2941-2950, by Yongyi Chen, Wangang Gong, and Yun Zhou et al. (1), was published with some errors and should be corrected as below:

(I) The dose of metformin " $1.0 \mathrm{mmol} / \mathrm{L}$ " in Figure 2 legend should be corrected as " $20 \mathrm{mM}$ ".

(II) The microRNA name in Figure 3 legend was incorrect that "miR-34a" should be corrected as "miR-107".

(III) In Y-axis of Figure 3D, "relative SGC-7901 proliferation" should be changed to "Expression of MAPK8".

The authors regret the errors and all the inconveniences caused.

Open Access Statement: This is an Open Access article distributed in accordance with the Creative Commons AttributionNonCommercial-NoDerivs 4.0 International License (CC BY-NC-ND 4.0), which permits the non-commercial replication and distribution of the article with the strict proviso that no changes or edits are made and the original work is properly cited (including links to both the formal publication through the relevant DOI and the license). See: https://creativecommons.org/ licenses/by-nc-nd/4.0/.

\section{References}

1. Chen $Y$, Gong W, Zhou Y, et al. Metformin up-regulated miR-107 expression and enhanced the inhibitory effect of miR-107 on gastric cancer growth. Transl Cancer Res 2020;9:2941-50.

Cite this article as: Chen Y, Gong W, Zhou Y, Fan R, Wu Y, Pei W, Sun S, Xu X, Jiang H. Erratum to metformin upregulated miR-107 expression and enhanced the inhibitory effect of miR-107 on gastric cancer growth. Transl Cancer Res 2020;9(11):7381. doi: 10.21037/tcr-2020-007 